\title{
Skeletal stem cell and bone implant interactions are enhanced by LASER titanium modification
}

\author{
Karin E. Sisti a, b, c, *, María C. de Andrés ${ }^{a}$, David Johnston ${ }^{\text {a }}$, Edson Almeida-Filho ${ }^{\text {b }}$, \\ Antonio C. Guastaldi ${ }^{\text {b }}$, Richard O.C. Oreffo ${ }^{\text {a }}$ \\ a Bone and Joint Research Group, Centre for Human Development, Stem Cells and Regeneration, Institute of Developmental Sciences, \\ University of Southampton, Southampton SO16 6YD, UK \\ ${ }^{\mathrm{b}}$ Biomaterials Group, Institute of Chemistry, São Paulo State University (UNESP), Box 355, Araraquara, Brazil \\ ${ }^{\mathrm{c}}$ Federal University of Mato Grosso do Sul (UFMS), Campo Grande, Brazil
}

\section{A R T I C L E I N F O}

\section{Article history:}

Received 23 September 2015

Accepted 2 October 2015

Available online 9 October 2015

\section{Keywords:}

Titanium surface

Skeletal stem cell

Tissue regeneration

Bone formation

LASER

\begin{abstract}
A B S T R A C T
Purpose: To evaluate the osteo-regenerative potential of Titanium (Ti) modified by Light Amplification by Stimulated Emission of Radiation (LASER) beam (Yb-YAG) upon culture with human Skeletal Stem Cells $\left(\right.$ hSSCs $\left.^{1}\right)$.

Methods: Human skeletal cell populations were isolated from the bone marrow of haematologically normal patients undergoing primary total hip replacement following appropriate consent. STRO- $1^{+}$ hSSC ${ }^{1}$ function was examined for 10 days across four groups using Ti discs: i) machined Ti surface group in basal media $\left(\mathrm{Mb}^{2}\right)$, ii) machined Ti surface group in osteogenic media $\left(\mathrm{Mo}^{3}\right)$, iii) LASER-modified Ti group in basal media $\left(\mathrm{Lb}^{4}\right)$ and, iv) LASER-modified Ti group in osteogenic media $\left(\mathrm{Lo}^{5}\right)$. Molecular analysis and qRT-PCR as well as functional analysis including biochemistry (DNA, Alkaline Phosphatase $\left(\mathrm{ALP}^{6}\right)$ specific activity), live/dead immunostaining (Cell Tracker Green $\left(\mathrm{CTG}^{7}\right)$ /Ethidium Homodimer-1 $\left(\mathrm{EH}-1^{8}\right)$ ), and fluorescence staining (for vinculin and phalloidin) were undertaken. Inverted, confocal and Scanning Electron Microscopy (SEM) approaches were used to characterise cell adherence, proliferation, and phenotype.

Results: Enhanced cell spreading and morphological rearrangement, including focal adhesions were observed following culture of hSSCs ${ }^{1}$ on LASER surfaces in both basal and osteogenic conditions. Biochemical analysis demonstrated enhanced $\mathrm{ALP}^{6}$ specific activity on the hSSCs ${ }^{1}$-seeded on LASERmodified surface in basal culture media. Molecular analysis demonstrated enhanced $\mathrm{ALP}^{6}$ and osteopontin expression on titanium LASER treated surfaces in basal conditions. SEM, inverted microscopy and confocal laser scanning microscopy confirmed extensive proliferation and migration of human bone marrow stromal cells on all surfaces evaluated.

Conclusions: LASER-modified Ti surfaces modify the behaviour of hSSCs. ${ }^{1}$ In particular, SSC ${ }^{1}$ adhesion, osteogenic gene expression, cell morphology and cytoskeleton structure were affected. The current studies show Ti LASER modification can enhance the osseointegration between Ti and skeletal cells, with important implications for orthopaedic application.
\end{abstract}

() 2015 Elsevier Inc. All rights reserved.

\section{Introduction}

Research in the field of biomaterials has advanced significantly

\footnotetext{
* Corresponding author. Bone and Joint Research Group, Centre for Human Development, Stem Cells and Regeneration, Institute of Developmental Sciences, University of Southampton, Southampton SO16 6YD, UK.

E-mail address: karinellensisti@gmail.com (K.E. Sisti).
}

in recent years driven in part by the desire to develop biomaterials that will provide extended longevity and enhanced performance for an increasing ageing population [1]. Bone tissue engineering seeks to address the unmet need for new tissues lost as a consequence of disease, trauma or ageing, using a raft of interdisciplinary approaches including developmental biology, materials science, stem cells and bioengineering. Typically, the approach is to harness the therapeutic potential of stem cells together with an appropriate biomaterial $[2,3]$. Ti has long been the gold standard for 
orthopaedic given the excellent biocompatibility, low corrosion, wear resistance and to promote osseointegration at the boneimplant interface [4]. For the development of osseointegration the recruitment of cells with osteogenic potential is essential. Subsequent colonisation by the cells is believed to occur through the release of growth factors and cytokines into the clot surrounding the site of implant placement, and it is widely accepted that SSCs ${ }^{1}$ are the first cells recruited to such sites in vivo [5]. While Ti implants have found clinical utility for many decades, the process of osseointegration remains, to date, unclear. The process is time dependent and is dependent upon the close relationship between the bone quality and the Ti surface, although the bone structure is naturally difficult to change, the Ti surface can be relatively easily modified [6]. There are two accepted approaches to enhance the material bone response - the first is the development of a rough topography optimised for bone response [7], and the second is the establishment of a high surface energy (wettability) rendering the surface super-hydrophilic, thereby facilitating initial cell contact and adherence $[8,9]$.

A number of approaches have been advocated to modify and improve the Ti surface, LASER treatment is an innovative approach that results in surfaces with increased surface area, enhanced wettability and, in preclinical (lapine) bone models, displays negligible corrosion and high removal torques of established implants [6]. As recently detailed in a number of studies, LASER treatment appears to provide a promising method for Ti implant generation, resulting in enhance and rapid onset of osseointegration [6,10-13].

Understanding how to control, manipulate, and enhance the intrinsic healing events modulated through osteogenic differentiation of SSCs ${ }^{1}$ through the application of modified surfaces offers significant potential for the orthopaedic field. It is clear that an exquisite interplay exists between the cells and the microtexture of a material. In vivo, cells encounter a number of topographical features ranging from protein folding to collagen banding [14]. Due to the ease of manufacture, the development of materials with a range of surface roughness has been widely used to further examine the bone material interface. Such a strategy provides useful information regarding the bone cell response to structured materials [15]; either as a consequence of surface modification that generates enhanced implant stability and/or indeed accelerated healing following implantation [16].

Based on the hypothesis that modified surfaces can modulate the initial osteo-inductive responses of cells, this study set out to examine the osteo-regenerative potential of Ti-modified by LASER beam (Yb-YAG) on $\mathrm{hSSC}^{1}$ compatibility and subsequent cell function.

\section{Methods}

\subsection{Cell culture}

Skeletal cell populations STRO- $1^{+}$hSSCs $^{1}$ were isolated and cultured following previously described protocols [17] with the approval of the Local Research Ethics Committee (LREC 194/99).

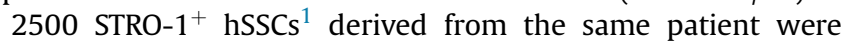
cultured on titanium discs in non-tissue culture plastic multiwell dishes for 10 days across four groups: $\mathrm{Mb},{ }^{2} \mathrm{Mo},{ }^{3} \mathrm{Lb}^{4}$ and Lo. ${ }^{5}$ Basal

\footnotetext{
${ }^{1}$ hSSCs(human Skeletal Stem Cells).

$2 \mathrm{Mb}$ (Machined Ti, basal media)

3 Mo(Machined Ti, osteogenic media).

${ }^{4}$ Lb(LASER-modified Ti, basal media).

${ }^{5}$ Lo(LASER-modified Ti, osteogenic media).
}

media was DMEM with $10 \%$ FCS and osteogenic media included $10 \mathrm{nM}$ dexamethasone.

\subsection{Ti discs}

Ti discs were prepared at UNESP(Araraquara/Brazil). 180 Ti rods were cut into $8 \mathrm{~mm}$ diameter by $2 \mathrm{~mm}$ long cylinders, and the surfaces of 90 discs were modified by LASER beam as described previously $[6,11,18]$. All samples were sterilized by ethylene oxide.

\subsection{Analysis of $h S S C^{1}$ proliferation and viability}

Cell number was determined using a standard DNA PicoGreen assay [18]. Cell lysate was measured for DNA content using PicoGreen (Molecular Probes, Paisley, UK) analysed using a BioTek FLx800 microplate fluorescent reader.

\subsection{Live/dead immunostaining}

$\mathrm{CTG}^{7}$ was used to label viable cells and $\mathrm{EH}-1^{8}$ for necrotic cell nuclei. Cell images were assessed for cell viability using Zeiss Axiovision software Ver 3.0 via an AxioCam HR digital camera on an Axiovert 200 inverted microscope (Carl Zeiss, Hertfordshire, UK) under fluorescent light.

\subsection{Analysis of the osteogenic differentiation of hSSCs $^{1}$}

$\mathrm{ALP}^{6}$ activity within the cell lysate was measured using $\mathrm{p}$ nitrophenyl phosphate as the substrate in 2-amino-2-methyl-1propanol alkaline buffer solution (Sigma, Poole, UK), analysed using a BioTek ELx-800 microplate reader to provide specific enzyme activity (ALP 6 /DNA/hr) across samples.

\subsection{Analysis of cell adherence and morphology, cytoskeleton structure and focal adhesion - confocal laser scanning microscopy}

The FAK100 | Actin Cytoskeleton/Focal Adhesion Staining Kit (Millipore ${ }^{\mathbb{R}}$ ) was used to analyse cytoskeleton modifications following culture of the hSSCs ${ }^{1}$ on the different Ti samples. In brief, cells were fixed in $4 \%$ formaldehyde in PBS, permeabilised $(0.1 \%$ Triton X-100 in PBS) and blocked (1\% BSA in 1\% PBS). Cells were incubated with a primary anti-vinculin mouse monoclonal antibody (1:100) and then with FITC-conjugated goat anti-mouse secondary antibody $(1: 100)$ and cultures were then stained simultaneously with TRITC-conjugated phalloidin (1:1000) (to enable labelling of actin filaments) and DAPI (1:1000 dilution of a $1 \mathrm{mg} / \mathrm{ml}$ sotck). The secondary antibody alone was used as a negative control. Images were taken using a confocal laser scanning microscope (Leica TCS SP5, Leica Biosystems, Wetzlar, Germany).

\subsection{SEM}

Samples were fixed whole in 3\% gluteraldehyde and $4 \%$ formaldehyde in $0.1 \mathrm{M}$ PIPES buffer at $\mathrm{pH}$ 7.2. A post-fixative of $1 \%$ osmium tetroxide was applied prior to dehydration through a series of graded alcohols followed by critical point drying. The surface was putter-coated with gold-palladium and visualized with an FEI Quanta 200 SEM (FEI, Oregon, USA) to observe the morphology and attachment of cells on the Ti surfaces.

\footnotetext{
${ }^{6}$ ALP(Alkaline Phosphatase).

7 CTG(Cell Tracker Green).

8 EH-1(Ethidium Homodmer-1).
} 


\subsection{Molecular analysis}

Following incubation of $\mathrm{hSSCs}^{1}$ on the different surfaces, samples were washed, incubated with collagenase IV, trypsinised and total RNA then extracted using RNeasy Plus Mini Kit (Invitrogen) to enable gene expression analysis. Extracted RNA was reverse transcribed using VILO cDNA synthesis kit (Invitrogen ${ }^{\circledR}$ ) for RT-PCR. qRT-PCR was performed using a 96-well optical reaction plate and a 7500 Real Time PCR system (Applied Biosystems, Carlsbad, USA). Each sample was subjected to qRT-PCR against a panel of osteogenic gene primers (Table 1 ). Values were calculated using the comparative threshold cycle $(\mathrm{Ct})$ method, normalized to $\beta$-actin expression and expressed as the mean \pm SD.

\subsection{Statistics}

All experiments were run three times using four independent samples. Data was expressed as the mean \pm SD. Statistical analysis was performed using SPSS v 17.0 (SPSS Inc, Chicago, IL/USA). The Wilcoxon's signed rank test was used to compare between groups. $P$ values less than 0.05 were deemed significant.

\section{Results}

\section{1. hSSCS $^{1}$ cultured on LASER-modified Ti surface display enhanced cell growth and viability}

No significant differences were observed after 10 days of culture of $\mathrm{hSSCs}^{1}$ seeded on any of the Ti surfaces $\left(\mathrm{Mb}^{2}\right.$ versus $\mathrm{Lb}^{4}$ $(100 \% \times 87.51 \%), \mathrm{Mo}^{3}$ versus $\left.\mathrm{Lo}^{5}(103 \% \times 160.22 \%)\right)$ indicating cell survival and growth (Fig. 1). Cell viability and an absence of cell necrosis were confirmed by live/dead staining with $\mathrm{CTG}^{7} / \mathrm{EH}-1^{8}$ after 10 days culture (Fig. $1 \mathrm{~A}-\mathrm{D}$ ).

\section{2. hSSCs ${ }^{1}$ cultured on LASER-modified Ti surface exhibit excellent biocompatibility, altered morphology, modified-cytoskeletal structures and focal adhesions}

To analyse the effects of the Ti surfaces on the hSSC ${ }^{1}$ cytoskeleton, fluorescence staining was performed with vinculin monoclonal antibody and TRITC-conjugated phalloidin. Enhanced cell spreading and cytoskeletal (actin) structure rearrangement was observed in cells cultured on the LASER-modified surface as analysed using confocal microscopy (Fig. 2B, D, F). Actin filaments (red) in $\mathrm{hSSCs}^{1}$ grown on machined surface were observed to be organized parallel to the underlying surface topography (Fig. 2A, C and E), while cells cultured on LASER-modified surfaces exhibited actin

\section{Table 1}

Human osteogenic gene primer sequences used for RT-PCR.

\begin{tabular}{|c|c|c|}
\hline Protein & Gene & Primer sequences \\
\hline B-Actin (housekeeping gene) & B-Actin & $\begin{array}{l}\mathrm{F}: 5^{\prime}-\text { GGCATCCTCACCCTGAAGTA } \\
\mathrm{R}: 5^{\prime} \text { - AGGTGTGGTGCCAGATTTC }\end{array}$ \\
\hline Alkaline phosphatase & $A L P$ & $\begin{array}{l}\mathrm{F}: 5^{\prime}-\mathrm{GGAACTCCTGACCCTTGACC} \\
\mathrm{R}: 5^{\prime}-\mathrm{TCCTGTTCAGCTCGTACTGC}\end{array}$ \\
\hline Collagen type $1 \mathrm{~A} 1$ & COL1A1 & $\begin{array}{l}\mathrm{F}: 5^{\prime} \text {-GAGTGCTGTCCCGTCTGC } \\
\mathrm{R}: 5^{\prime} \text {-TTTCTTGTTCGGTGGGTG }\end{array}$ \\
\hline $\begin{array}{l}\text { Runt-related transcription } \\
\text { factor } 2\end{array}$ & RUNX2 & $\begin{array}{l}\mathrm{F}: 5^{\prime}-\mathrm{GTAGATGGACCTCGGGAACC} \\
\mathrm{R}: 5^{\prime} \text {-GAGCTGGTCAGAACAAAC }\end{array}$ \\
\hline $\begin{array}{l}\text { Sex-determining region } \mathrm{Y} \text {, } \\
\text { box } 9\end{array}$ & SOX9 & $\begin{array}{l}\mathrm{F}: 5^{\prime} \text {-CCCCAACAGATCGCCTACAG } \\
\mathrm{R}: 5^{\prime} \text {-GAGTTCTGGTCGGTGTAGTC }\end{array}$ \\
\hline Osteopontin & OPN & $\begin{array}{l}\mathrm{F}: 5^{\prime}-\mathrm{GTTTCTCAGACCTGACATCC} \\
\mathrm{R}: 5^{\prime}-\mathrm{CATTCAACTCCTCGCTTTCC}\end{array}$ \\
\hline Osteocalcin & OCN & $\begin{array}{l}\mathrm{F}: 5^{\prime}-\mathrm{GGCAGCGAGGTAGTGAAGAG} \\
\mathrm{R}: 5^{\prime}-\mathrm{CTCACACACCTCCСТCCTG}\end{array}$ \\
\hline
\end{tabular}

filaments arranged randomly (Fig. 2B, D, F). hSSC ${ }^{1}$ focal adhesion formation was evidenced by vinculin staining (green) and presented at the cell periphery on LASER modified surface (Fig. 2F, J). In contrast, the actin filaments of hSSCs ${ }^{1}$ cultured on machined surface were oriented in a predominantly parallel manner (Fig. 2A, C, E, G, I, K).

\subsection{SEM}

Used for cell adherence and morphology following growth of hSSCs. ${ }^{1}$ hSSCs ${ }^{1}$ exhibited discrete differences in cell morphology as a function of profile surface and media. All groups displayed healthy adherent cells on Ti surfaces (Fig. 3). On machined surface, cells presented as flattened structures, with a distinct spread morphology. On $\mathrm{Mb}^{2}$ surfaces, hSSCs ${ }^{1}$ displayed few protoplasmic processes attached to the surface (Fig. 3I). Cells were observed to be distributed over the LASER surface and to form cytoplasmic bridges of variable thickness, suspended above the peaks and depressions of the LASER-modified surface (Fig. 3B and D). On the LASERmodified surfaces, the hSSCs ${ }^{1}$ presented numerous protoplasmic processes (Fig. 3F, H, J and L). Filopodia were shown as a consequence of culture in osteogenic culture media (Fig. $3 \mathrm{~K}$ and $\mathrm{L}$ ).

\subsection{LASER-modified Ti surface enhance osteogenic differentiation of $h_{S C C S}{ }^{1}$}

To investigate the effect of $\mathrm{hSSCs}^{1}$ differentiation on LASERmodified surfaces after 10 days in culture, the expression of osteogenic markers was analysed using biochemical and molecular approaches. ALP ${ }^{6}$ specific activity was increased in hSSCs ${ }^{1}$ cultured on LASER-modified surfaces compared to hSSCs ${ }^{1}$ cultured on control (machined) surfaces, in basal culture media (154.28\% vs $100 \%$ $\mathrm{Mb}^{2}$ control) (Fig. 1).

Molecular analysis showed that hSSCs ${ }^{1}$ seeded on $\mathrm{Lb}^{4}$ displayed enhanced osteogenic marker gene expression in comparison to hSSCs $^{1}$ cultured on $\mathrm{Mb}^{2}$

Specifically, $A L P^{6}$ and OPN mRNA levels in hSSCs ${ }^{1}$ cultured on $\mathrm{Lb}^{4}$ were respectively 2-fold and 3.6-fold higher than those cultured in $\mathrm{Mb}^{2}$ (Fig. 4).

\subsection{Osteogenic conditions do not modulate hSSCs ${ }^{1}$ cultured on LASER-modified Ti surface}

The induction of proliferation and osteogenic differentiation of hSSCs ${ }^{1}$ were assessed using standard osteogenic culture medium with samples from the same patients cultured on machined and LASER surfaces. Results revealed that the hSSCs ${ }^{1}$ did not show any statistically significant increases in cell proliferation (mean \pm SD $103 \pm 20.94$ versus $160 \pm 8.27$ ) (Fig. 1 ), ALP $^{6}$ specific activity (mean SD $124.71 \pm 33.78$ versus $134.78 \pm 23.11)$ and osteogenic marker gene expression $A L P^{6}$ (mean \pm SD $4.82 \pm 1.190$ versus $8.814 \pm 4.98$ ) and $O P N$ (mean \pm SD $1.2 \pm 0.84$ versus $0.76 \pm 0.09$ ) (Fig. 4 ) or any cytoskeleton modification (Fig. 2).

\section{Discussion}

Ti surface modification to enhance implant function can be achieved using a variety of methods. In the current study we demonstrate the efficacy of LASER irradiation of titanium to generate a surface to improve skeletal stem cell function. LASER irradiation has been shown to be a promising method for Ti surface treatment, increasing the Ti surface area, wettability and, critically, offering a high degree of surface purity at relatively low cost $[11,12,19]$. Furthermore, studies with LASER-modified materials implanted in rabbit tibias and subsequently presenting high 

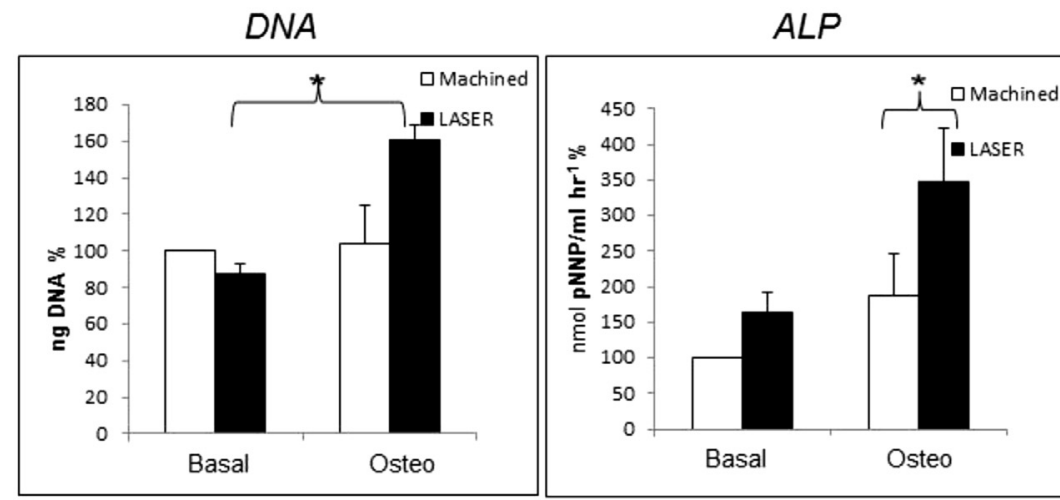

\section{Specific Activity ALP/DNA}
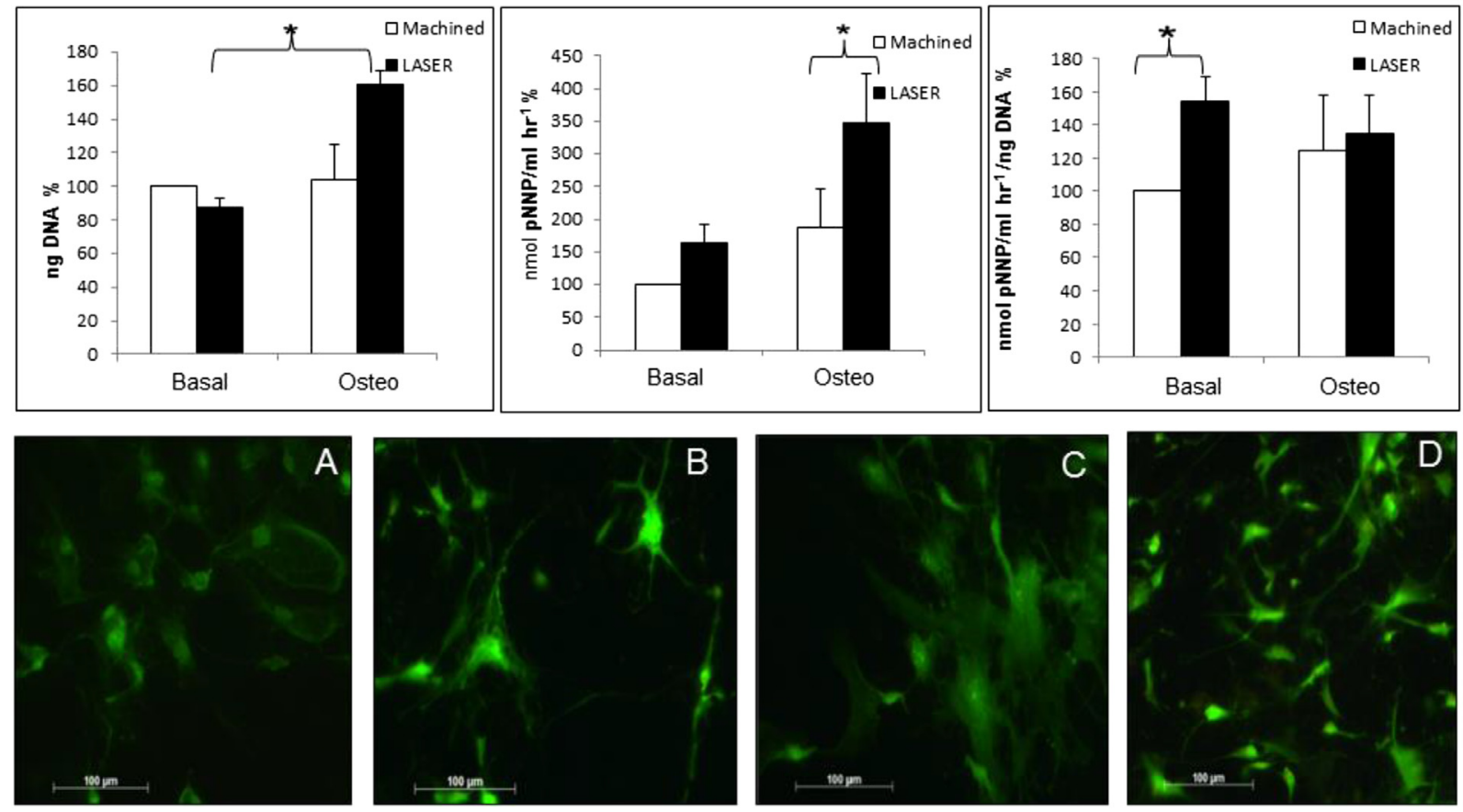

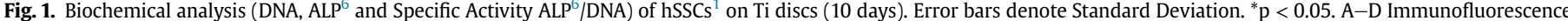
(cell tracker green - inverted microscope 20X magnification, scale bar $=100 \mu \mathrm{m}$ ) of hSSCs ${ }^{1}$ (10 days) on $\mathrm{Mb}^{2} \mathrm{Lb}^{4} \mathrm{Mo}^{3}$ and $\mathrm{Lo}^{5}$

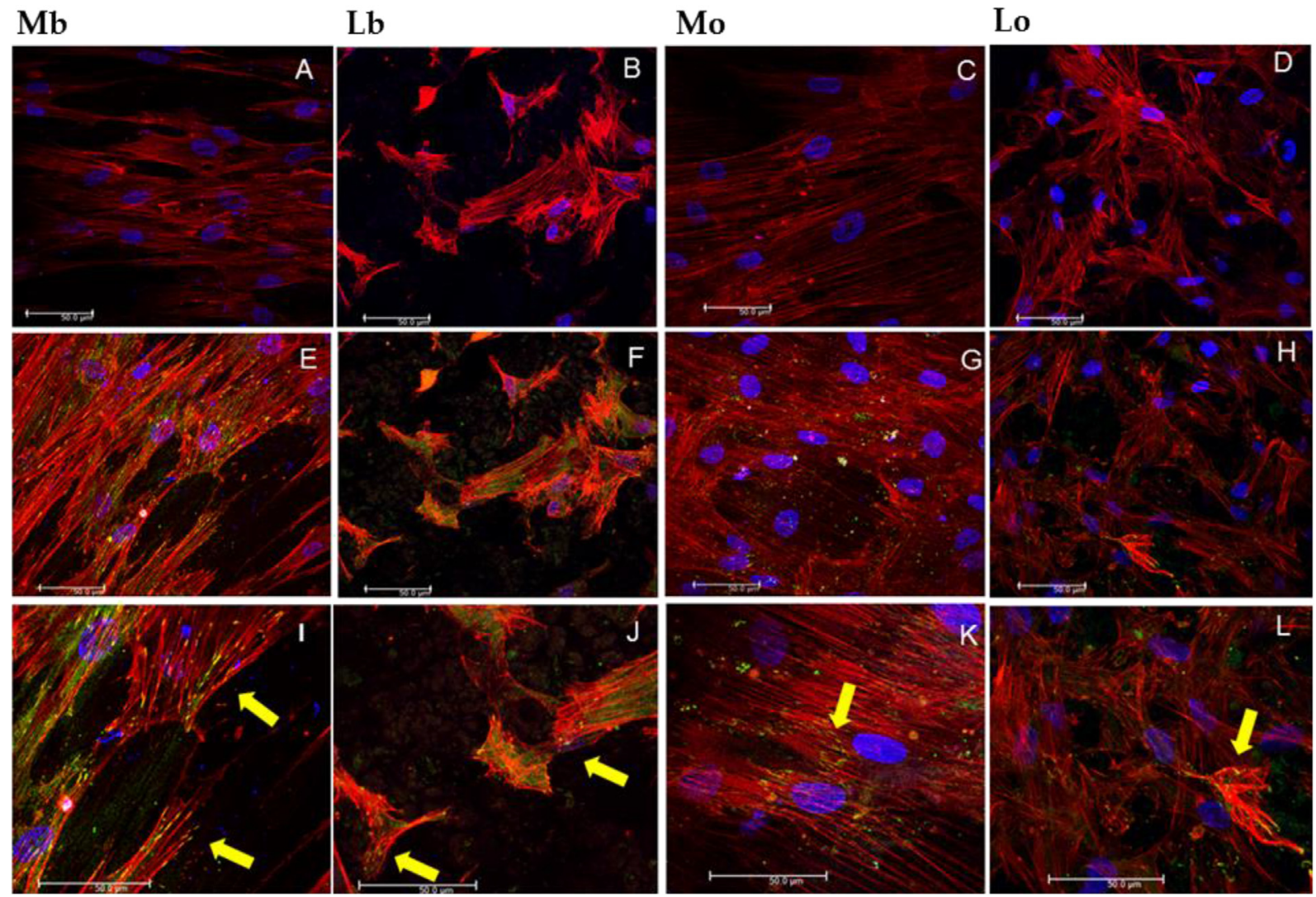

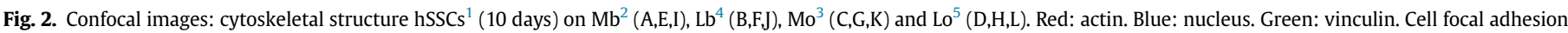
(arrows). Scale bar $=50 \mu \mathrm{m}$. 

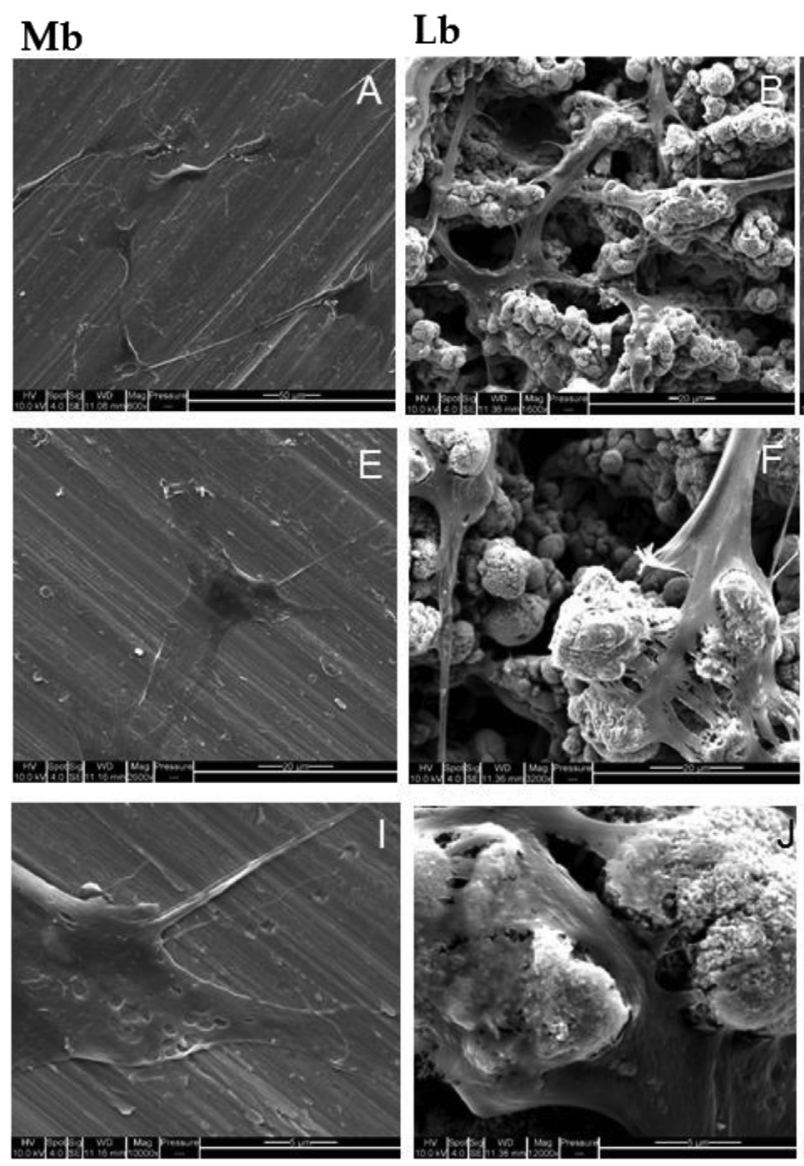

Lb

Mo
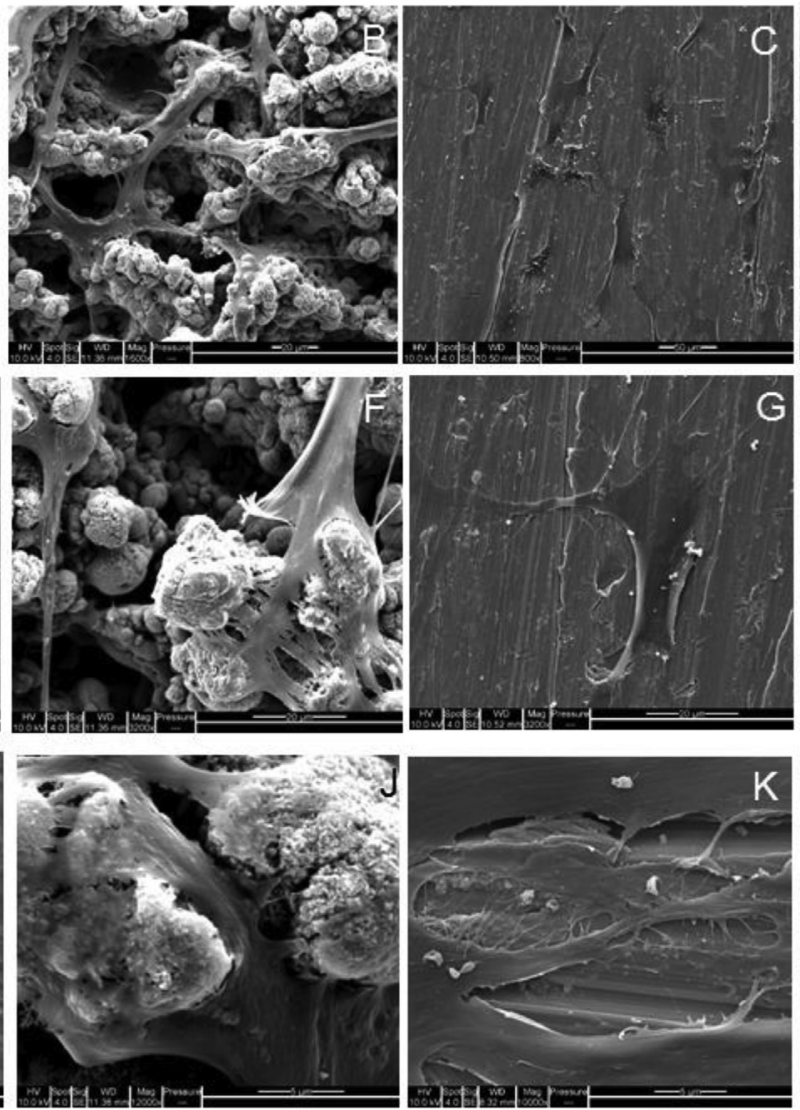

Lo
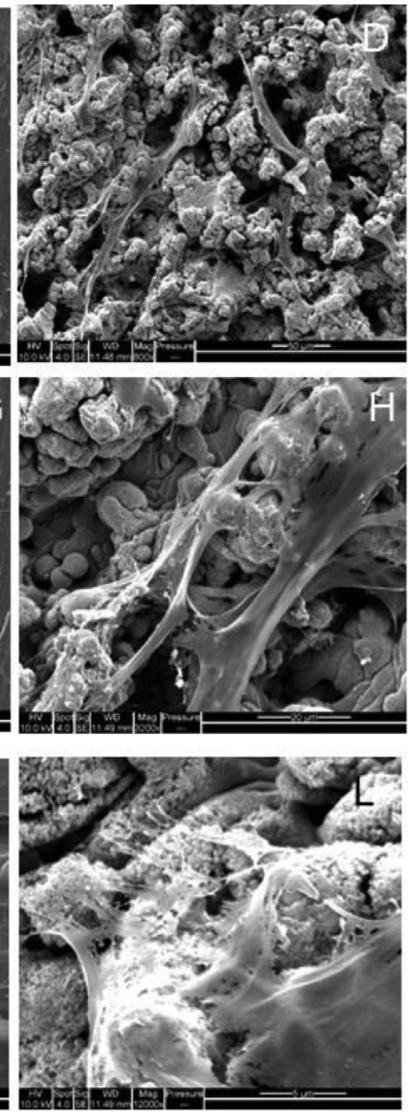

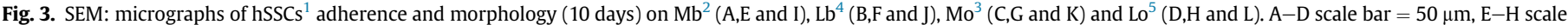
bar $=20 \mu \mathrm{m}$ and $\mathrm{I}-\mathrm{L}$ scale bar $=5 \mu \mathrm{m}$.

ALP

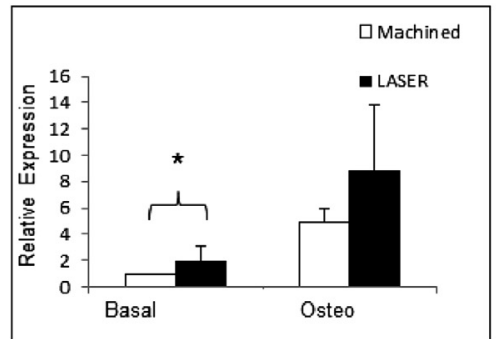

OCN

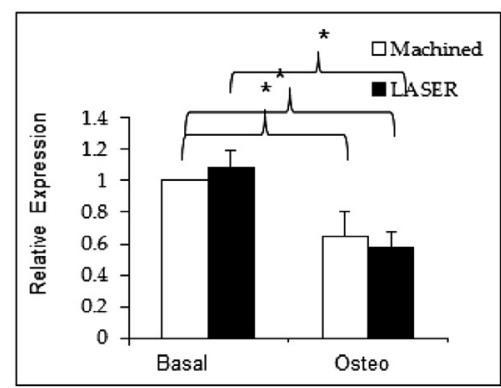

RUNX2

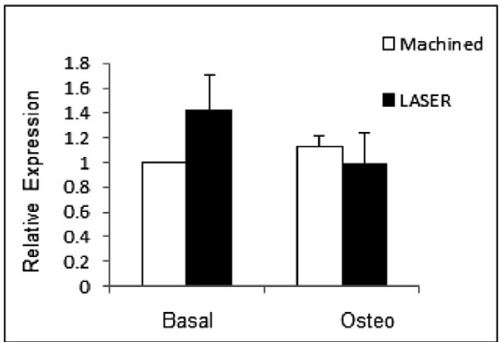

OPN

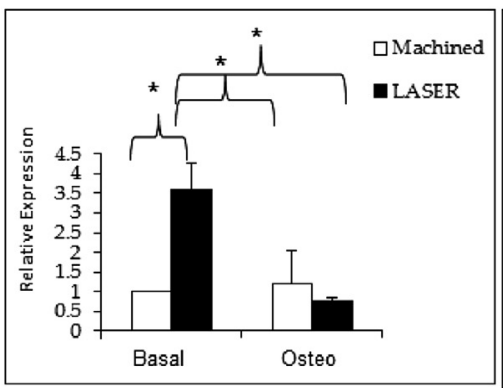

Col1A1

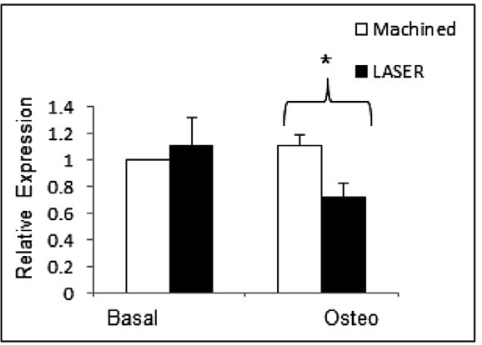

SOX9

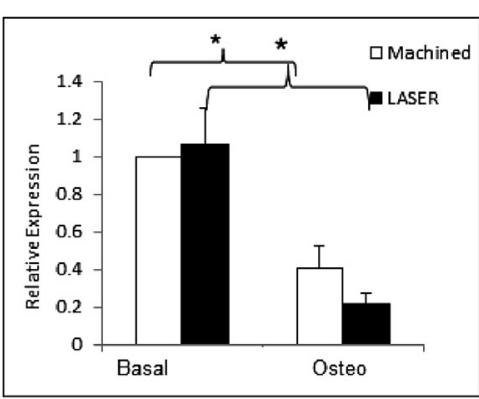

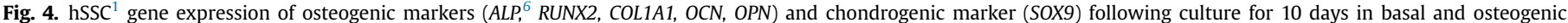
conditions, on machined surface and LASER Ti surfaces ( $\beta$-actin $=$ internal control). Values are mean \pm SD of 4 independent samples, ${ }^{*} \mathrm{p}<0.05$ ). 
removal torques $[11,12,19]$ and properties that favour cell adhesion and proliferation make this an attractive approach $[10,20]$. We have previously shown that the topography of a Ti LASER-modified surface displays distinct topographies including a surface roughness with an appearance comparable to a "cauliflower" morphology that provide enhanced wettability and surface area [6].

The biocompatibility of biomaterials is closely related to cell viability and proliferation with attachment, adhesion, and spreading in the early phase of the cell/material interaction being critical in modulating the capacity of a cell to proliferate and differentiate [21]. The LASER treated surfaces in the current study, provide a topography that supported $\mathrm{hSSC}^{1}$ viability and proliferation. A wealth of studies indicate rough Ti surfaces can enhance osseointegration in the clinic in comparison to smooth surfaces $[6,7,12,22]$, although the cellular and molecular mechanisms that drive this process remain far from clear. ALP ${ }^{6}$ activity is typically used as a marker to follow the differentiation of osteoblasts from non-calcium-depositing to calcium-depositing cells [23], and as a marker of the early stages of osteogenic differentiation [24]. Studies suggest the ALP ${ }^{6}$ activity of a cell is surface-dependent. Thus, if the Ti surface is modified elevated ALP ${ }^{6}$ activity is a likely consequence [25]. In the current study, hSSCs ${ }^{1}$ on LASER-modified Ti surfaces, displayed enhanced differentiation as assessed by $\operatorname{ALP}^{6}$ activity. It is assumed this is a consequence of enhanced material surface reactivity [26] and enhanced physical-chemical properties [6]. In contrast, Takeuchi et al. showed that a modified surface can reduce cell proliferation whilst initially driving the expression of specific cell markers except for $\operatorname{ALP}^{6}$ [27]. The cell-biomaterial interface functions not only to define the boundary between tissue and implant, but also to act as a mediator of first stage protein interactions as well as later stage cell adhesion and orientation [28]. When blood cells arrive at the implant Ti surface, the blood cells express a variety of integrins, resulting in cytoskeletal changes. Changes in cytoskeleton tension have a direct effect on cell morphology as evidenced by actin staining. Alteration in cell morphology as a consequence of cytoskeletal tension has an indirect effect on mechano-transduction pathways, as demonstrated by expression changes in stem cell responses [14,29]. In the current studies cytoskeletal rearrangement were observed, including altered expression patterns of vinculin, a key structural component of focal adhesions [30]. On the LASER topography, vinculin displayed arrangement around the cell cytoplasm periphery. Interestingly, expression of the vinculin marker was spread distinctly revealing an extensive non focal distribution in the cytoplasm of $\mathrm{hSSCs}^{1}$ on the machined surface. Furthermore, hSSCs ${ }^{1}$ cultured on machine surfaces displayed a flat morphology, primarily orientated along the discrete grooves, with relatively few protoplasmic processes attached to the Ti substrate. In contrast, cells cultured on LASER Ti discs displayed enhanced adherence to the modified surface, indicating the potential for modified cellular activity or tissue responses leading to greater osteogenesis [3].

We have previously reported that changes in cytoskeletal tension in response to topography may modify interphase nucleus organisation and hence directly influence cell gene expression profiles $[14,31]$. The pattern of five specific osteogenic markers, RUNX2, ALP, ${ }^{6}$ COL1A1, OPN and OCN and, the chondrogenic marker SOX9, in primary hSSCs ${ }^{1}$ cells cultured on LASER Ti surfaces were compared with machined Ti surface substrates. RUNX2 is essential for osteoblast maturation and osteogenesis [32] and is a key regulator of $O C N, C O L 1$ and $A L P^{6}$ genes [33]. $A L P^{6}$ and COL1A1 are matrix-mineralizing proteins, and their expression has been shown to be important for bone matrix assembly [34]. In the present study $A L P^{6}$ gene expression showed a statistically significant increase from $\mathrm{Mb}^{2}$ to $\mathrm{Lb},{ }^{4}$ in agreement with other studies [35]. The mechanisms of bone remodelling underline the potential role of two non-collagenous matrix proteins, osteopontin and osteocalcin [36]. Osteopontin is a multifunctional phosphorylated glycoprotein secreted by osteoblasts, and has been suggested to be present at an early stage of bone development and to promote the attachment of osteoblasts to the extracellular matrix [37]. Osteopontin is involved in bone remodelling [38] whilst osteocalcin is a marker of primary bone formation and is produced by osteoblasts [39]. While the precise role of osteocalcin is still under examination, roles as an endocrine regulator of metabolism in the skeleton and as a regulator of mineralization have been proposed. Serum concentrations of osteocalcin have been shown to correlate with histomorphometric indices of newly formed bone [40]. The present study show that hSSCs ${ }^{1}$ cultured on LASER-modified Ti surfaces display enhancee osteopontin expression, indicating the possible osteogenic potential of LASER-modified Ti surfaces. Interestingly, no significant changes in osteocalcin expression were observed in the current study, in agreement with previous studies [41]. This may potentially be as a consequence of osteocalcin being a late marker of bone cell differentiation and osteopontin an early marker [42]. Although, COL1A1, RUNX2 and OCN expression did not show statistical significant differences across the substrates, a trend of enhanced expression on LASER-modified surfaces was observed. As expected, SOX9 expression, a chondrocytic marker was unaffected.

In conclusion, this study demonstrated the influence of the microtexture of LASER-modified Ti surfaces on the behaviour of hSSCs. ${ }^{1}$ Cell proliferation, adhesion, osteogenic gene expression, cell morphology and cytoskeleton structure were all affected by the modified topography of Ti surfaces that resulted from LASER irradiation. These studies show the potential of Ti LASER modification to enhance the osseointegration at the material-bone cell interface with important implications for orthopaedic and dental application.

\section{Acknowledgements}

The authors thank Franco Conforti, Atsushi Takahashi and Anton Page for technical advice; and Lindsey Goulston for critical advice on this paper. Funding for this work is gratefully acknowledged from the following: Science without border Scholarship code (10331-12-3) for K.E.S. from CAPES/Brazil. Work in the Oreffo laboratory is funded through the BBSRC (BB/GO105791), EU (MarieCurie IRSES) and MRC (MR/K026682/1). We gratefully acknowledge the provision of bone samples by the orthopaedic surgeons at Southampton General Hospital.

\section{Transparency document}

Transparency document related to this article can be found at http://dx.doi.org/10.1016/j.bbrc.2015.10.013.

\section{References}

[1] M. Geetha, A.K. Singh, R. Asokamani, A.K. Gogia, Ti based biomaterials, the ultimate choice for orthopaedic implants-a review, Prog. Mater. Sci. 54 (3) (2009) 397-425.

[2] J.I. Dawson, E. Kingham, N.R. Evans, E. Tayton, R.O.C. Oreffo, Skeletal regeneration: application of nanotopography and biomaterials for skeletal stem cell based bone repair, Inflamm. Regen. 32 (2012) 72-89.

[3] J.I. Dawson, J. Kanczler, R. Tare, M. Kassem, R.O. Oreffo, Concise review: bridging the gap: bone regeneration using skeletal stem cell-based strategies where are we now? Stem Cells 32 (2014) 35-44.

[4] P.I. Branemark, Osseointegration and its experimental background, J. Prosthet. Dent. 50 (1983) 399-410.

[5] J.E. Davies, Mechanisms of endosseous integration, Int. J. Prosthodont. 11 (1998) 391-401.

[6] K.E. Sisti, A. Piattelli, A.C. Guastaldi, T.P. Queiroz, R. de Rossi, Nondecalcified histologic study of bone response to titanium implants topographically modified by laser with and without hydroxyapatite coating, Int. J. Periodont. Restor. Dent. 33 (2013) 689-696.

[7] A. Wennerberg, T. Albrektsson, Effects of titanium surface topography on bone 
integration: a systematic review, Clin. Oral Implants Res. 20 (Suppl. 4) (2009) $172-184$.

[8] H.C. Lai, L.F. Zhuang, X. Liu, M. Wieland, Z.Y. Zhang, Z.Y. Zhang, The influence of surface energy on early adherent events of osteoblast on titanium substrates, J. Biomed. Mater. Res. A 93 (2010) 289-296.

[9] G. Zhao, High surface energy enhances cell response to titanium substrate microstructure, J. Biomed. Mater. Res. Part A 74 (2005) 49-58.

[10] R.S. Faeda, H.S. Tavares, R. Sartori, A.C. Guastaldi, E. Marcantonio Jr., Biological performance of chemical hydroxyapatite coating associated with implan surface modification by laser beam: biomechanical study in rabbit tibias, J. Oral Maxillofac. Surg. 67 (2009) 1706-1715.

[11] K.E. Sisti, R. de Rossi, A.M. Antoniolli, R.D. Aydos, A.C. Guastaldi, T.P. Queiroz, I.R. Garcia Jr., A. Piattelli, H.S. Tavares, Surface and biomechanical study of titanium implants modified by laser with and without hydroxyapatite coating, in rabbits, J. Oral Implantol. 38 (2012) 231-237.

[12] F.A. Souza, T.P. Queiroz, A.C. Guastaldi, I.R. Garcia-Junior, O. Magro-Filho, R.S. Nishioka, K.E. Sisti, C.K. Sonoda, Comparative in vivo study of commercially pure Ti implants with surfaces modified by laser with and without silicate deposition: biomechanical and scanning electron microscopy analysis, J. Biomed. Mater. Res. B Appl. Biomater. 101 (2013) 76-84.

[13] T. Traini, C. Mangano, R.L. Sammons, F. Mangano, A. Macchi, A. Piattelli, Direct laser metal sintering as a new approach to fabrication of an isoelastic functionally graded material for manufacture of porous titanium dental implants, Dent. Mater. 24 (2008) 1525-1533.

[14] M.J. Dalby, N. Gadegaard, R.O. Oreffo, Harnessing nanotopography and integrin-matrix interactions to influence stem cell fate, Nat. Mater. 13 (2014) $558-569$.

[15] M.M. Stevens, J.H. George, Exploring and engineering the cell surface interface, Science 310 (2005) 1135-1138.

[16] N. Logan, P. Brett, The control of mesenchymal stromal cell osteogenic differentiation through modified surfaces, Stem Cells Int. 2013 (2013) 361637.

[17] D. Howard, K. Partridge, X. Yang, N.M. Clarke, Y. Okubo, K. Bessho, S.M. Howdle, K.M. Shakesheff, R.O. Oreffo, Immunoselection and adenoviral genetic modulation of human osteoprogenitors: in vivo bone formation on PLA scaffold, Biochem. Biophys. Res. Commun. 299 (2002) 208-215.

[18] B.J. Bolland, K. Partridge, S. Tilley, A.M. New, D.G. Dunlop, R.O. Oreffo, Biological and mechanical enhancement of impacted allograft seeded with human bone marrow stromal cells: potential clinical role in impaction bone grafting, Regen. Med. 1 (2006) 457-467.

[19] C.M. Stanford, Surface modification of biomedical and dental implants and the processes of inflammation, wound healing and bone formation, Int. J. Mol. Sci. 11 (2010) 354-369.

[20] F.J.C. Braga, Rodrigo F.C. Marques, E. Almeida-Filho, A.C. Guastaldi, Surface modification of Ti dental implants by Nd:YVO4 laser irradiation, Appl. Surf. Sci. 253 (2007) 6.

[21] K. Anselme, Osteoblast adhesion on biomaterials, Biomaterials 21 (2000) 667-681.

[22] A. Sanz, A. Oyarzun, D. Farias, I. Diaz, Experimental study of bone response to a new surface treatment of endosseous titanium implants, Implant Dent. 10 (2001) 126-131.

[23] F.S.H. Kaplan, W.C. Hayes, T.M. Keaveny, A. Boskey, T.A. Einhorn, J.P. Iannotti, Form and function of bone, in: Orthopedic Basic Science, 1994.
[24] J.R. Farley, D.J. Baylink, Skeletal alkaline phosphatase activity as a bone formation index in vitro, Metabolism 35 (1986) 563-571.

[25] M.F. Maitz, R.W. Poon, X.Y. Liu, M.T. Pham, P.K. Chu, Bioactivity of titanium following sodium plasma immersion ion implantation and deposition, Biomaterials 26 (2005) 5465-5473.

[26] P. Habibovic, K. de Groot, Osteoinductive biomaterials-properties and relevance in bone repair, J. Tissue Eng. Regen. Med. 1 (2007) 25-32.

[27] K. Takeuchi, L. Saruwatari, H.K. Nakamura, J.M. Yang, T. Ogawa, Enhanced intrinsic biomechanical properties of osteoblastic mineralized tissue on roughened titanium surface, J. Biomed. Mater. Res. A 72 (2005) 296-305.

[28] M.J. Biggs, R.G. Richards, S. McFarlane, C.D. Wilkinson, R.O. Oreffo, M.J. Dalby, Adhesion formation of primary human osteoblasts and the functional response of mesenchymal stem cells to 330nm deep microgrooves, J. R. Soc. Interface 5 (2008) 1231-1242.

[29] S. Lavenus, V. Trichet, S. Le Chevalier, A. Hoornaert, G. Louarn, P. Layrolle, Cell differentiation and osseointegration influenced by nanoscale anodized titanium surfaces, Nanomed. Lond. 7 (2012) 967-980.

[30] S.R. Coyer, A. Singh, D.W. Dumbauld, D.A. Calderwood, S.W. Craig, E. Delamarche, A.J. Garcia, Nanopatterning reveals an ECM area threshold for focal adhesion assembly and force transmission that is regulated by integrin activation and cytoskeleton tension, J. Cell Sci. 125 (2012) 5110-5123.

[31] M.J. Dalby, N. Gadegaard, P. Herzyk, D. Sutherland, H. Agheli, C.D. Wilkinson, A.S. Curtis, Nanomechanotransduction and interphase nuclear organization influence on genomic control, J. Cell Biochem. 102 (2007) 1234-1244.

[32] T. Kokubo, H.M. Kim, M. Kawashita, Novel bioactive materials with different mechanical properties, Biomaterials 24 (2003) 2161-2175.

[33] T. Alliston, L. Choy, P. Ducy, G. Karsenty, R. Derynck, TGF-beta-induced repression of CBFA1 by Smad3 decreases cbfa1 and osteocalcin expression and inhibits osteoblast differentiation, EMBO J. 20 (2001) 2254-2272.

[34] V.V. Rani, L. Vinoth-Kumar, V.C. Anitha, K. Manzoor, M. Deepthy, V.N. Shantikumar, Osteointegration of titanium implant is sensitive to specific nanostructure morphology, Acta Biomater. 8 (2012) 1976-1989.

[35] G.S. Stein, J.B. Lian, Molecular mechanisms mediating proliferation/differentiation interrelationships during progressive development of the osteoblast phenotype, Endocr. Rev. 14 (4) (1993) 424-442.

[36] T. Takano-Yamamoto, T. Takemura, Y. Kitamura, S. Nomura, Site-specific expression of mRNAs for osteonectin, osteocalcin, and osteopontin revealed by in situ hybridization in rat periodontal ligament during physiological tooth movement, J. Histochem. Cytochem. 42 (1994) 885-896.

[37] J.X. Zhu, Y. Sasano, S. Kamakura, S. Kusunoki, I. Mizoguchi, Expression of major bone extra cellular matrix proteins during embryonic osteogenis in rat mandibles, Anat. Embryol. 202 (2000) 7.

[38] M. Mazzali, T. Kipari, V. Ophascharoensuk, J.A. Wesson, R. Johnson, Osteopontīna - a molecule for all seasons, Q. J. Med. 95 (2002) 3-13.

[39] A.J. Lee, S. Hodges, R. Eastell, Measurement of osteocalcin, Ann. Clin. Biochem. 37 (4) (2000) 432-446.

[40] C. Desbois, G. Karsenty, Osteocalcin cluster: implications for functional studies, J. Cell Biochem. 57 (1995) 379-383.

[41] I. Jankovska, M. Pilmane, I. Urtane, Osteopontin and osteocalcin in maxilla tissue of skeletal class III patients, Stomatologija 11 (2009) 125-128.

[42] W.T. Butler, The nature and significance of osteopontin, Connect. Tissue Res. 23 (1989) 123-136. 